\title{
La ciudad narrada: Revuelta y semántica del conflicto urbano
}

\section{CARLOSDIZ}

carlos.diz.reboredo@gmail.com - Grup de Recerca sobre Exclusió i Control Socials (GRECS), Universitat de Barcelona, España

Fecha de recepción: 20 de abril de 2017

Fecha de aceptación: 12 de mayo de 2017

\section{RESUMEN}

A partir del relato de un episodio concreto de mi trabajo de campo etnográfico, desarrollado en Copenhague en 2009, trataremos de analizar el papel de la ciudad en los recientes movimientos sociales. Desde el final del movimiento antiglobalización a las revueltas urbanas de la segunda década del siglo XXI, la ciudad se ha convertido en un objeto central del debate político, social y epistemológico. Un objeto central de los discursos y las narrativas contemporáneas. Describiendo la revuelta y el conflicto urbano desde un punto de vista simbólico y material, pero también semántico, atenderemos a una semántica del conflicto urbano que nos revela una ciudad narrada compuesta de múltiples voces y líneas argumentales. El conflicto social, inherente a la vida urbana y a la cotidianidad del activismo y los movimientos sociales, se analiza aquídesde el punto de vista de los imaginarios, las historias y las narraciones. Contraponiendo los discursos de las élites a los discursos activistas, se observarán también los procesos de marketización y empresarialismo ur- bano así como la retórica de la ciudad marca y la ciudad creativa.

PALABRAS CLAVE: Ciudad, conflicto social, conflicto urbano, movimientos sociales, semántica.

\section{ABSTRACT}

I will analyse the role of the city in the recent social movements from the starting account of a specific episode of my ethnographic fieldwork, developed in Copenhagen in 2009. From the end of the anti-globalization movement to the urban revolts of the second decade of the $21^{\text {st }}$ century, the city has become a central object of political, social and epistemological debate. A central issue of contemporary discourses and narratives. Describing revolt and urban conflict from a symbolic and material point of view, but also semantically, I will deal with a semantics of urban conflict that reveals a narrated city composed of multiple voices and plot lines. Social conflict, inherent to the urban life and to the everyday life of activism and social movements, is analysed here from the point of view of imaginaries, histories and narratives. Contrasting the discourses of the elites to the activist ones, the processes of marketization and urban entrepreneurialism as well as the rhetoric of the brand city and the creative city will also be observed in this paper.

KEYWORDS: City, semantics, social conflict, social movements, urban conflict. 


\section{INTRODUCCIÓN: LA CIUDAD NARRADA}

"Capítulo primero. Él adoraba Nueva York... Era su ciudad y siempre lo sería".

Película Manhattan, Woody Allen

Estamos hechos de historias tanto como de piel y huesos. También las ciudades lo están. Recorremos sus calles y avenidas, mas también sus relatos y memorias. La ciudad se cuenta a sí misma. La contamos. Nos es contada. La atravesamos y nos atraviesa. Ponemos nuestros cuerpos en parques y plazas, nuestras palabras en revistas, películas, canciones y novelas. Las ponemos en la prensa, en la radio o en la televisión y con ellas construimos e imaginamos la ciudad (García Canclini, 1997). Su trama urbana, sus pasajes, sus mapas, sus discursos que la sostienen. Sus materializaciones y subjetividades. Su complejidad. Su cacofonía: "Una ciudad siempre es heterogénea, entre otras razones, porque hay muchos imaginarios que la habitan” (García Canclini, 2007, p. 91).

No por casualidad, desde los inicios de la era industrial, la ciudad se fue convirtiendo en el espacio literario preferido de los escritores, allá donde se funden realidad, mito e invención (Capdepón, 2015). Pero al igual que ocurre con la ficción, lo imaginario - en su sentido sustantivado- no es lo contrario de la realidad sino una forma de esculpir en ella, de agregarle nombres, escenas, valores, historias, paisajes y personajes, multiplicándola y abriéndola a lo posible (Rancière, 2010). Lo imaginario, así pues, está preñado de intención poiética; es decir, su función radica en producir y potenciar la realidad, creándola y recreándola, inventándola y reinventándola, trazando dinámicamente significados y representaciones (Castoriadis, 1989; Vera, 2014). Por ello, la ciudad narrada es un laberinto, un cruce de mitos. Historias y contrahistorias, relatos y contrarrelatos cuya lógica estriba en ser contados y compartidos, en pasar y ser pasados, en estar en movimiento. El mito es habla y es mensaje, es metalenguaje (Barthes, 2009), y es a través suyo - o en su contra- que la comunidad halla su sentido, se imagina, se reivindica o se sitúa en el mundo. Con un valor abierto e inacabado, los mitos son historias que invitan a ser recogidas, renarradas y actualizadas. Las ciudades y los imaginarios urbanos que las recorren nos recuerdan que existe una "vida social delas historias" (Jackson, 2002), y que estas siempre implican otras y a otros, y siempre dan que hablar.

En las últimas décadas, imbuidas en un tempo acelerado tan propio del tardocapitalismo, las ciudades han pasado a ocupar - tanto en el plano de las élites como en el campo de la sociedad civil y de los movimientos socialesuna posición central en el debate contemporáneo. Huelga decir que hoy en día, en la vorágine neoliberal agudizada tras la crisis financiera internacional desatada en 2008, los distintos discursos sobre la urbe guardan una relación 
intrínseca con la disputa por el poder de enunciación y por la apropiación del espacio interpretativo (Reguillón, 2008). En este sentido, entre las palabras y las cosas, cabe indicar que existe una materialidad social de los discursos, y que estos son producidos siempre en un contexto y desde un lugar, obedeciendo a intereses, inquietudes y sensibilidades concretas. "Los relatos que circulan en la sociedad no son azarosos, infundados, gratuitos o caóticos, sino que corresponden a razones prácticas de sujetos sociales en conflicto por la producción y distribución tanto delo material como del sentido" (Alonso \& Fernández,2013, p. 15). Por lo tanto el conflicto, inherente a la vida urbana, se plasma también en las distintas maneras de narrar la ciudad.

Hoy, más de la mitad de la población mundial vive en áreas urbanas (Naciones Unidas, 2014). Al añejo mareo vertical, brotado en las cimas de los rascacielos, le sucede ahora un "vértigo horizontal" (Villoro, 2002), producido por una expansión kilométrica de la urbe contemporánea. En este contexto, rara vez puede leerse la ciudad como antaño, esto es, como una unidad discreta, en lo material y en lo geográfico, en lo político y en lo económico, en lo moral y en lo simbólico, en lo étnico y en lo nacional, en lo social. Volcada hacia el exterior desde mediados del siglo XX, desbordadas y reconfiguradas sus fronteras por la vía de la urbanización expansiva, sus límites se vuelven cada vez más porosos y difusos. Con sus luces y sombras, la urbanización alcanza por todo el planeta su clímax histórico, al tiempo que las ciudades se vuelven laboratorios de lo global y condensan los procesos vigentes en la sociedad (Cucó, 2004). Esta tendencia ala metropolización y a la difusión urbana convierte las ciudades en espacios-frontera nutridos y salpicados de múltiples diferencias, sitios donde lo global se espacializa y enclaves privilegiados desde donde reimaginar la globalización (García Canclini, 2000).

He ahí la importancia de pensar la ciudad como objeto múltiple y descentrado, y ya no como una forma espacial delimitada de manera precisa e independiente. Si bien los estudios urbanos han tendido a enfatizar históricamente la unidad ontológica de la ciudad, reificándola como un objeto geométrico en un espacio euclidiano, debemos ahora mirar a ese vasto horizonte vertiginoso de un modo más flexible y dinámico, sabiendo que la multiplicidad de la ciudad contemporánea hace a esta enredarse en redes híbridas y translocales, integrada en lógicas interdependientes de circulación. Así, los “ensamblajes urbanos" (Farías, 2011) dan cuenta de esta creciente complejidad, compuestos coralmente en la conjunción de materias, agentes, infraestructuras y tecnologías, pero también en la articulación y el entrecruzamiento de discursos, representaciones, historias y narraciones.

Nadie duda ya del protagonismo actual de las ciudades. Nutridas de la concentración geográfica de excedentes de producción, se sitúan en el eje de una relación mutuamente dependiente entre urbanismo y capitalismo (Harvey, 2013). Relación que no ha hecho sino agudizarse bajo el presente paradigma 
de la globalización neoliberal, llevando a las ciudades - en una era de riesgo, inestabilidad y precariedad generalizadas - a comportarse y gobernarse a sí mismas como empresas, desplegando creativamente estrategias de boosterism, de "marca" o "autopromoción", y ejecutando la transición del modelo gestor de la sociedad welfarista de los años sesenta al modelo emprendedor y de empresarialismo urbano iniciado en la década de los ochenta (Harvey, 2007; Peck, 2014). Y frente a esta narrativa dominante que pone a la ciudad y a la sociedad al servicio del mercado (y no al revés), no son pocas las expresiones de rebeldía y descontento que - por todo el mundo- surgen de la mano de activistas y movimientos sociales. Expresiones que actualizan el "giro espacial" que, al calor de las revueltas populares, estalló con la crisis urbana de la década de 1960, y que potenció la conciencia de las interrelaciones entre espacio y poder (Soja, 2009). Por aquel entonces, y en consecuencia, surgió una suerte de economía política urbana, de corte marxista, caracterizada por el análisis crítico de los conflictos citadinos y de los procesos de urbanización y producción social del espacio de las ciudades (Castells, 2004; Harvey, 1979; Lefebvre, 2013). Desde entonces aquella conciencia no ha hecho sino crecer. Al mismo tiempo, a la mundialización y urbanización del capital le ha venido acompañando la mundialización y urbanización de la resistencia.

En la segunda década del siglo XXI hemos visto emerger, en distintas geografías, movimientos diversos como el 15M español, el Passe Livre brasileño, el Occupy norteamericano, el \#YoSoy 132 mexicano, la Nuit Debout francesa o las protestas turcas en torno al parque Gezi, entre otros. Pese a sus diferencias, todos compartían varios rasgos en común, entre otros: convertir la ciudad en eje y objeto principal de sus luchas y proclamas: ya no sólo es el escenario de la acción sino aquello mismo que estaba en juego. Si la "escapada" o la "huida" de la metrópolis se presentaba otrora como condición sine qua non para la puesta en marcha de un proyecto "contracultural" (Gómez-Ullate, 2009), la alternativa para el activismo contemporáneo parece pasar ahora, primero, por hacer de la ciudad su principal lugar para la política, el núcleo duro de sus prácticas y discursos. Al fin y al cabo, como indicaba Manuel Castells (1986), los movimientos sociales urbanos encarnan subjetivamente las alternativas y los imaginarios de otros "proyectos de ciudad".

De este modo, contra un relato dominante que ha querido normalizar y naturalizar la globalización neoliberal, anhelando homogeneizar las ciudades del planeta, los recientes levantamientos urbanos dan prueba de la asimétrica distribución de bienes, recursos y derechos, demostrando que "ellugar" - pensado como el "otro" de una globalización del capital soñada sin límites geográfi$\cos$ (Escobar, 2000) - halla en la ciudad su foco mayor de réplica y resistencia. Si es cierto que el Estado social se debilita en beneplácito de organismos y corporaciones transnacionales - al contrario que el Estado penal, que va en aumento (Wacquant, 2010) - y si al proceso globalizador lo acompañan los 
paradigmas dela deslocalización, la flexibilización y las lógicas económicas del postfordismo - perdiendo así fuerza la presencia y el imaginario de instancias de trabajo y representación previas, como la fábrica, el sindicato o el partido-, la urbe se convierte entonces en el lugar de referencia. Más próxima y accesible que el Estado, se vuelve un lenguaje para la protesta y la reivindicación, un enclave desde el que replantear nuevas formas y nuevos derechos de ciudadanía (Caldeira \& Holston, 2005; Sassen, 2003).

Tomemos, por ejemplo, el caso del 15M en España. Tanto con su emergencia en 2011, tomando las plazas del país mediante acampadas en los centros urbanos, como en su desarrollo los años siguientes, acompañando procesos de autogestión política, generando asambleas populares en los barrios, creando huertos urbanos en terrenos baldíos, okupando edificios vacíos contra los desahucios y otras acciones, el movimiento ha generado otra narrativa urbana, entendiendo la intervención directa y material en la urbe como una "intervención democrática” (Diz, 2016b; Holston, 1999). Las acampadas o los huertos han generado otros relatos de la ciudad, de sus usos y posibilidades. Si a través de la arquitectura siempre se han contado historias - sobre todo la historia del poder (Sennett, 1997) —, la arquitectura popular y rebelde de estas expresiones - los bancales de un huerto construido para fomentar la cultura comunitaria y el consumo colectivo, las infraestructuras de una acampada erigida para contestar la crisis, defender la participación frente a la representación, exigir democracia directa, etc. - cuenta también su propia historia, ya sea esta precaria o inestable. Además, entre las prácticas y materializaciones en el espacio urbano y los discursos elaborados en Internet y en las redes sociales aparecen nuevos géneros narrativos y otras maneras de comunicar y contar la ciudad (Estalella, 2016). Tal es el caso, sugiere Estalella, de lo que ocurre con los procesos de documentación y archivo de los huertos urbanos madrileños: la creación de vídeos, $b \log s$, tutoriales en YouTube o documentos literarios donde se explica cómo autoconstruirlos supone un ejercicio de reescritura material del guion urbano. Es decir, si la ciudad construida nos propone un guion concreto que disciplina nuestro modo de estar y de actuar en el espacio, el hecho de reconstruirlo y reimaginarlo desafía su lectura y escritura tradicional. Por ello, dirá el autor, la ciudad que se rebela es también una ciudad que se revela, en tanto se hace visible y legible al narrar y compartir su propio guion urbano.

En este artículo, sin embargo, nos detendremos un poco antes en el tiempo para tomar perspectiva de estos últimos años de movilizaciones y conflictos urbanos, narrando un episodio de campo vivido en la ciudad de Copenhague en diciembre de 2009, en los albores de lo queluego resultó ser una devastadora crisis financiera de escala internacional. Durante la primera década del siglo XXI, el llamado movimiento "antiglobalización" presentó batalla en numerosas "contracumbres", contestando en las calles a las políticas y a las grandes reuniones de organismos como el G8, el Fondo Monetario Internacional, la Or- 
ganización Mundial del Comercio y el Banco Mundial(Diz,2016a) ${ }^{1}$. Aunquela ciudad, qué duda cabe, ya constituía para estos activistas su hábitat primordial, no sería hasta bien entrada la crisis y hasta bien sentidos sus efectos - ya en la segunda década de este siglo- cuando los levantamientos urbanos enfatizarían con mayor ahínco la estrecha relación, por un lado, entre las lógicas de explotación, mercantilización y privatización del espacio urbano y la estafa financiera, y por otro, el poderoso vínculo entre las luchas por la democracia y las crecientes intervenciones materiales en la ciudad.

A finales de 2009, en lo que más de un activista definió como un impasse e intermezzo, el por aquel entonces debilitado movimiento antiglobalización se encontró por última vez y con relativo éxito en las frías calles de la capital danesa. Una ciudad que, durante varias semanas, funcionó como una metáfora salvaje de lo que estaba por venir, una conjunción a la vez rebelde y disciplinada de imaginarios, subjetividades y materializaciones. Durante elCOP15, lalucha por la ciudad implicaba directamente una lucha simbólica y material por el sentido y el significado ${ }^{2}$. Implicaba batallar con palabras y por las palabras. Narrar la ciudad suponía contar sus tramas, sus derivas, sus conflictos.

Primero enmarcaremos, brevemente, la contracumbre del clima de 2009 y mi etnografía sobre el activismo. A continuación, y tomando aquel episodio como eje central del análisis, comentaremos algunos de los procesos de marketización y empresarialización de lo urbano. Al mismo tiempo y a lo largo del texto, atenderemos a las múltiples narrativas que cuentan y dan cuenta dela ciudad, explicando cómo dichas narraciones ponen de manifiestola multiplicidad de imaginarios que la recorren. Esta multinarración y esta multivocalidad delo

1 Estas protestas o "contracumbres" funcionaban como grandes ceremonias colectivas, manifestaciones rituales que desplegaban sobre el espacio urbano una suerte de arquitectura en red, fraguada entre las calles y el ciberespacio; de hecho, su irrupción era siempre precedida de una intensa labor en Internet, y los movimientos que allí confluían se conectaban o hipervinculaban como los hotlinks de sus páginas web (Klein, 2001), actuando como hackers que intentaban deconstruir -en lugar de máquinas-ideas dominantes, en base a una lógica del enjambre, descabezada, descentralizada y sin forma fija (Juris, 2008). Aquellosjóvenes activistas-mayormenteblancosy declase media-que contestaban el "finaldela historia" augurado por los conservadores en la década de 1990 (Fukuyama, 1992), lo hacían desde una alternativa altermundialista descontenta con la izquierda tradicional (partidos, sindicatos). En su día a día, la cotidianidad activista producía "otros lugares de la política" (Diz, 2017), labrados en los círculos ordinarios de las asambleas, en barrios, okupas o centros sociales autogestionados. En cambio, las contracumbres se revelaban como algo puntual y extraordinario, y el éxito de la de Seattle en 1999 -contra la OMC- sembró el camino a los encuentros venideros en el nuevo siglo, por ejemplo en Europa: Praga, Génova, Barcelona, Rostock, Florencia... Una pluralidad de tácticas y colectivos se manifestaba en estas citas, de la acción directa y violenta del Black Bloc a las protestas festivas y carnavalescas; del campesinado del Sur Global al estudiantado europeo indignado; de las marchas y bloqueos a Foros Mundiales y cumbres alternativas. De cumbre en cumbre, la respuesta social a la globalización neoliberal ponía de manifiesto las conexiones transnacionales y macroestructurales que la reconfiguración del capital imponía en todas partes, pero también globalizaba la indignación y la resistencia. Así, de ciudad en ciudad, estos encuentros escenificaban unos dramas del lenguaje donde el habla circulaba, se mediatizaba y se politizaba, y así los activistas hablaban a través de estos eventos, que marcaban como fechas, lugares e hitos en el camino, reconstruyendo y narrando a través de ellos -cronotópicamente y de manera intertextual- sus propios mitos y genealogías.

2 Conferencia de las Partes (COP, en sus siglas en inglés). Organizada por la Convención Marco de la ONU sobre el Cambio Climático, entrada en vigor en 1994 y que celebra conferencias anuales desde 1995. Los más de 190 países que han ratificado el tratado forman las llamadas Partes de la Convención. En este caso, la decimoquinta Conferencia sobre el Cambio Climático de la ONU (COP15) tenía como objetivo sellar un nuevo acuerdo internacional jurídicamente vinculante sobre el clima, listo para reducir la emisión de gases de efecto invernadero y presto a ser aplicado a partir de 2012, año en que expiraba el Protocolo de Kioto. 
urbano será analizada a través de un acercamiento a la semántica del conflicto incorporada y visibilizada por el activismo. También, a partir del estudio de caso de la "ciudad libre" de Christiania, en Copenhague, problematizaremos el concepto de ciudad creativa y los procesos de regeneración urbana que tienden a acompañarla. Para concluir, y en consonancia con la actualidad de las recientes revueltas urbanas, recordaremos que las prácticas de estos movimientos sociales llevan implícitas otras narraciones de la ciudad, debiendo entender la ciudad narrada en la complejidad de sus tramas dialógicas y en la intersubjetividad articulada de espacios, cuerpos, lenguajes y relaciones de poder.

\section{HISTORIAS DE COPENHAGUE}

A finales de la pasada década, antes de que su presencia mediática se atenuase por la crisis económica, el cambio climático se anunciaba como la amenaza más urgente. La lucha por la salud del planeta y por la "justicia climática”, decían los activistas, era la única capaz de convocar en las calles a decenas de miles de personas, tras el repliegue de varios años que parecía haber fulminado las grandes movilizaciones de inicios de siglo, estancadas desde las masivas convocatorias contra la guerra de Irak del año 2003. Y así fue. En diciembre de 2009, en Copenhague, la última de las grandes contracumbres - al menos en Europa y en términos de asistencia, con manifestaciones de hasta 100.000 personas - tuvo lugar ante la presencia de líderes políticos de todo el mundo y el despliegue de un enorme dispositivo policial. El COP15, la cumbre de la ONU sobre el cambio climático, se vio contestada por una sucesión de eventos, acciones y protestas. Sabedores de que la crisis climática no era una cuestión aislada sino un síntoma más de un capitalismo despiadado, y sabiendo también que en la "sociedad del riesgo global" los riesgos rompen las fronteras estatales y devienen amenazas supranacionales (Beck, 2006), activistas de distintos orígenes y escuelas políticas (ecologistas, autónomos, comunistas, anarquistas, etc.) articulaban sus voces y suscuerpos contra el floreciente capitalismo del desastre, esto es, aquel que "aprovecha momentos de trauma colectivo para dar el pistoletazo de salida a reformas económicas y sociales de corte radical" (Klein, 2007, p. 30). O por decirlo con uno de sus lemas: "Our climate, not your business".

Realizando un trabajo de campo etnográfico y multisituado sobre el activismo contemporáneo - investigación que me llevó por distintos puntos del continente europeo entre 2008 y 2012, y que presenté más adelante en mi tesis doctoral (Diz, 2016a) - , llegué a Dinamarca siguiendo las rutas de varios activistas gallegos, a los que me uní durante la contracumbre. Convocados y coordinados vía Internet por el Climate Collective y la red activista de "Acción por la Justicia Climática" o Climate Justice Action (CJA), compartimos durante una semana - junto a miles de activistas de otros países - los espacios de una vieja fábrica cerrada y deslocalizada hacía años (Ragnhildgade), donde dormíamos 
y nos resguardábamos del crudo invierno tras cada jornada de protestas y movilizaciones. Sin embargo, ya en nuestra primera mañana en la capital, siendo retenidos, cacheados y registrados por la policía al salir a la calle, pudimos advertir la dificultad que sería en aquellos días moverse libremente por la ciudad. $\mathrm{Al}$ igual que en el resto de jornadas, la policía actuaba no sólo en los lugares de acción, allí donde se celebraban las marchas y concentraciones, sino que lo hacía también anticipadamente y en clave preventiva, allí donde aparecían sujetos "sospechosos", en los lugares de descanso o de reunión, a la salida de sitios como Ragnhildgade. En otras palabras y con cierta ironía, Copenhague no se nos antojaba tan "abierta" en nuestra primera mañana en la ciudad...

Meses antes de la cumbre de las Naciones Unidas, Wonderful Copenhagen, oficina local de turismo, había lanzado una campaña publicitaria que no dejaba de anunciarse por doquier y de cosechar admiración: cOPENhagen. Open for you. Prescindiendo del topónimo danés København, con menorgancho quesu versión inglesa, el eslogan se unía a una moda global deseosa en convertir - con juegos de palabras - el nombre de su ciudad en un logotipo creador de tendencia. Lo mismo había ocurrido, por ejemplo, con I Amsterdam y LondON, entre otras. He ahí el ingenioso lema: "Copenhague. Abierta para ti”. En palabras de sus creadores, querían resaltar su carácter "abierto" (open) y "creativo", con el objetivo de tomar posiciones "en la intensa lucha de las capitales europeas por atraer turistas y negocios internacionales". Por supuesto, la flexibilidad era un elemento clave, y por ello la ciudad debía estar abierta a "inversiones", "experiencias" y "negocios"3. Es decir, narrar la ciudad para venderla como una marca. Un proceso que, lejos de ser excepcional, ha devenido la tónica dominante en nuestra era: una ciudad volcada hacia el turismo y convertida en marca, gobernada y gestionada como una empresa privada; la consolidación, en suma, del "empresarialismo urbano" iniciadoen los 80 (Harvey,2007). Una estrategiaala que se han unidociudadesque se enredan e interconectan jerárquicamente, cruzadas por intereses económicos y geopolíticos. Ciudades que aspiran a ser "mundiales" (Hannerz, 1998) o "globales" (Sassen, 2003), y que aglutinan puestos y tareas de comando, innovación y coordinación, acogiendo grupos financieros y empresariales, élites políticas y culturales o sedes de corporaciones transnacionales, y concentrando recursos y ciertos perfiles de población. Sin embargo, como en un juego de cuerpos y palabras, tal narración quedaba abierta a la interpretación, sucediéndose en aquellos días otras combinaciones lingüísticas y otros giros semánticos.

Durante el COP15, la "guía de acciones" distribuida por CJA dibujaba un mapa de lugares habitado por activistas, centros sociales, sitios de reunión y convergencia, espacios autónomos, media-center, puntos de acción y de información, etc. "Un mapa poliédrico de múltiples áreas políticas", como decía uno de los activistas gallegos, que reescribía subjetivamente el mapa oficial con una topografía alternativa de la protesta.

3 Para más información: En línea: www.opencopenhagen.com, www.visitcopenhagen.com 
Figura 1: Espacios activistas en el COP15, Mike Shand

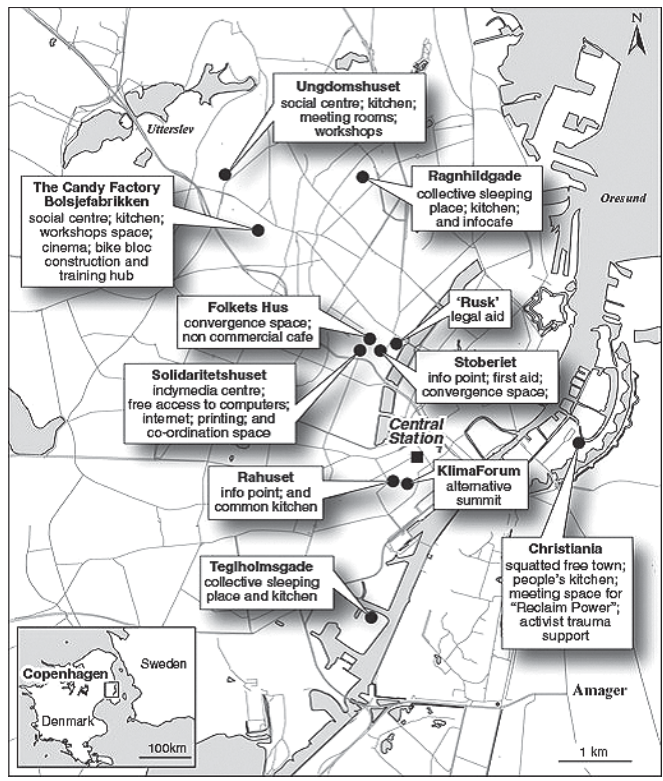

Fuente: Climate Justice Action (2009).

Sobre este mapa de la urbe (figura 1), diferente de cualquier plano o guía turística - y un mapa es siempre un relato, una narración-, cinco espacios se destacaron durante el COP15: el Bella Center, espacio oficial de la cumbre de la ONU, situado en las afueras; Hopenhagen, sitio corporativo ubicado junto al ayuntamiento en el centro urbano; el Klima Forum, cumbre alternativa celebrada en un pabellón deportivo y sede de colectivos de base y ONG de todo el mundo; espacios autónomos como la fábrica de Ragnhildgade o el barrio de Christiania; y las calles de la ciudad, escenario de marchas, desfiles festivos, arrestos masivos y violencia (Chatterton, Featherstone, \& Routledge, 2012). A cada uno de estos espacios, más o menos oficiales y que mostraban la multiplicidad de imaginarios que pueblan la ciudad, le correspondería un cuerpo, un lenguaje y una narración propios.

\section{ENTRE MAPAS Y PALABRAS: LA CIUDAD SEMÁNTICA}

Las ciudades son el punto de máxima tensión del sistema social, lugares para el encuentro, el conflicto y la diferencia. Las contracumbres tan sólo acentúan la ya de por sí compleja trama urbana. En ellas, los espacios se resignifican y acogen pleno sentido cultural al ser dramatizados y ritualizados por la vía de trifulcas y manifestaciones. En las tareas de alteración y alterización quedan 
reconfigurados los relatos, los símbolos, los mapas y las prácticas que les dan vida. En este caso, el juego de cuerpos y palabras que antes refería se articulaba a través de un lenguaje de sitios (Kuper, 2003) o entre sitios. Durante el COP15, entre la red de espacios antes visualizada, el mapa oficial de $c O P E N$ hagen mutaba al compás de las protestas, y los sucesivos renombramientos de la ciudad nos recordaban que - al igual que los símbolos - los lugares vividos son también "multivocales" (Rodman, 2003), esto es, activas construcciones político-subjetivas y no pasivos contenedores de prácticas. Un multivocalismo que da pie a una polifonía de voces y narraciones. Como decíamos al principio, contamos la ciudad tanto como nos es contada, hablamos a través de ella tanto como ella lo hace a través de nosotros.

De "ciudad abierta" a "ciudad esperanza", cual ciudad semántica en un cuento de Italo Calvino (2013); como si el topónimo se volviese un paisaje de palabras, palimpsesto fugaz capaz de inscribir y borrar sobre sí mismo anotaciones culturales enfrentadas. Hopenhagen: la ciudad esperanzada (del inglés hope: esperanza). En este caso, la agencia Ogilvy \& Mather — con más de 450 oficinas en todo el mundo y reconocida por su trabajo para firmas como Ford, Adidas o Telefónica - fue la encargada de diseñar la campaña, impulsada por la ONU y la Asociación Internacional de Publicidad, y que fue presentada en junio de 2009 en el Festival de Creatividad de Cannes. La campaña, aupada por multinacionales comoSiemens, BMW o Coca-Cola yencargada para elCOP15 por el entonces Secretario General de Naciones Unidas, Ban Ki-moon, era presentada - para indignación de muchos activistas, que hablaban de "reapropiación corporativa", "estrategia comercial", "lavado de cara" o "neutralización de las proclamas de cambio estructural" - como "movimiento de acción global" destinado a alcanzar la firma de un nuevo tratado sobre el clima. La agencia creó la web Hopenhagen.org (hoy ya en desuso), donde más de seis millones de personas dejaron su "mensaje de esperanza" y pudieron convertirse con un solo clic en "ciudadanos de Hopenhagen", obteniendo sin dificultad su "pasaporte Hopenhagen".

La campaña se extendió a nivel internacional gracias al uso de Internet y a su elevado presupuesto. Recién llegados a la ciudad, Hopenhagen nos daba la bienvenida desde cada rincón: vallas publicitarias, paradas de autobús, fachadas de edificios y andamios de obra oportunamente disimulados. Junto a la alcaldía, en una instalación presidida por un globo terráqueo de unos veinte metros de diámetro, se proyectaban imágenes de la cumbre y se mostraban, en color verde, los "mensajes de esperanza" recogidos en la web. Asimismo, anuncios de patrocinadores como el de Coca-Cola se desplegaban por todas partes, destapando para el viandante una "botella de esperanza" $-A$ Bottle of Hope - de la que brotaban alegres pajarillos, un sol radiante y una apacible campiña, rezumando a marketing social e "hipocresía institucionalizada" (Boehnert, 2011). 
Así, mientras unos obtenían con un clic "pasaporte" virtual para la ciudad esperanza, otros eran retenidos en sus fronteras y registrados por la policía antes de continuar su viaje. Había quien corría peor suerte y era devuelto a su país. En aquellos días, con un portentoso dispositivo de control transnacional dispuesto en el interior del continente para frenar la contracumbre, muchos controles se establecieron en las fronteras con Suecia y Alemania, pero otros tuvieron lugar ya no en suelo danés sino en sus propios territorios, en una operación de externalización de fronteras que "cerraba" los límites de $c O P E N$ hagen más allá de los lindes de su ciudad. De este modo, para anticiparse a los movimientos de cuerpos y sujetos no bienvenidos y considerados "peligrosos", las fronteras devenían artefactos flexibles y maleables, desplegables aquí o allá, difíciles de limitar y materializar - como antaño- en el mapa político de la modernidad, allí donde cesaba una soberanía y empezaba la otra, y donde la frontera era una línea clara e inamovible sobre el terreno (Balibar, 2005).

Ante este panorama, los itinerarios activistas, bien entre países o bien entre distintos puntos de Copenhague, se veían afectados por este control de la movilidad. En los propios barrios, los registros, los controles de identidad y las detenciones preventivas funcionaban como fronteras internas que marcaban los cuerpos a través de los sitios y demarcaban a su vez los sitios de cada cuerpo. Al mapa físico, pues, se le sumaba un mapa moral que zonificaba los usos de la ciudad y vedaba ciertos lugares. También se dificultaba el acceso de los activistas al centro urbano y a los puntos de reunión del COP15, y se acordonaban los espacios ligados a la red de Climate Justice Action.

\section{CONTROL Y CONFLICTO EN LA CIUDAD POLICIAL}

Una vez más, la ciudad era renombrada. Ante las detenciones preventivas, los arrestos masivos y el contundente despliegue policial, los activistas tiraban de ironía y escribían un nuevo nombre a través de folletos, flyers, listas de correo electrónico, blogs, páginas web, Indymedia o pintadas hechas al paso de manifestaciones ${ }^{4}$. Enfrentando la marca de "ciudad abierta" de cOPENhagen, proponían otro nombre más acorde con sus vivencias: la llamaban COPenhagen, algo así como "policilandia" o "ciudad policial", pues por ello

4 La ciudad se narraba a través de múltiples soportes. La escritura simbólica de los cuerpos en la calle se acompañaba dela escritura física con pintadas y grafitis, o en soportes de papel como pasquines y carteles. Además, en Internet se generaban otros tantos relatos. El impasse de aquella contracumbre tenía también que ver con el momento tecnológico delCOP15. En 2009, redes sociales 2.0 como Twitter o Facebook apenas habían entrado en Europa, olo habían hecho con poca fuerza. La comunicación activista a través de mailinglistsy portales de "contra-información" como Indymedia era todavía dominante. Apenas se había iniciado la transición a la lógica cultural de la "agregación" (Juris, 2012), aquella que se hizo presente en el 15M u Occupy varios años después, y que agregaba gente en las calles a través de la inmediatez y la viralidad de una comunicación trenzada vía smartphones y redes sociales. Con todo, este "ecosistema mediático" modificaba los procesos de producción de información, donde los activistas eran a un tiempo productores, editores y distribuidores (Tascón \& Quintana, 2012). Un ecosistema que gira en torno a la comunicación y a lenguajes híbridos e intertextuales, generando subjetividades y universos narrativos. Las nueves "redes de la política", cabe decir, revelarían otro tiempo y otro espacio para la narración, albergando géneros como el "microrrelato" en Twitter, donde el usuario tiene restringido el uso de caracteres, también usado por dirigentes políticos como un espacio de debate y promoción (Baggiolini \& Castro Rojas, 2016). 
resaltaban en mayúsculas el término cop, "poli” en inglés coloquial. Ciudad abierta, ciudad esperanza, ciudad policial. Ciudad reescrita. Para uno de los activistas gallegos, la capital danesa se convertía aquellos días en un "laboratorio de técnicas represivas" que, según él, habrían de expandirse por el continente en los próximos años, pasando de una situación de "emergencia" y "excepción" a su consolidación como herramientas "legisladas" y "normalizadas". Con el tiempo, y con ejemplos como la aprobación en España de la Ley de Seguridad Ciudadana de 2014 ("Ley Mordaza"), parece que su análisis era acertado. Hoy, los recortes sociales generados en un contexto de crisis, el incremento del control urbano y de la intervención policial, la llamada "ecología del miedo" (Davis, 2001) y la securitización de lo social por la vía de un discurso de la inseguridad se han ido consolidando en nuestras ciudades (Rivas, 2016). A su vez, los procesos de marketización urbana suelen correr parejos a este incremento del Estado penal y policial; he ahí, como ejemplo, los recientes casos de violencia urbanística (desalojos, reasentamientos urbanos, crímenes, militarización, etc.) sucedidos en Brasil en el marco del Mundial y los Juegos Olímpicos.

El "cordón sanitario" dispuesto alrededor de Ragnhildgade, por ejemplo, quería contener la amenaza encarnada por los activistas y sitiar sus cuerpos en zonas limítrofes. Cuerpos "manchados", pues sobre ellos recaía el estigma del desorden y la amenaza, representando la "suciedad" de lo que no está donde le corresponde; materia fuera de lugar cuya impureza no anida tanto en su materialidad como en su concreta distribución en el espacio, y que cabía limpiar y mantener fuera de contacto (Douglas, 2007). Frente a ello, las trayectorias activistas operaban como recorridos rituales, volviendo expresiva a la ciudad. De los puntos de convergencia a los sitios de acción, de las viejas fábricas al centro urbano, del parlamento danés a la esfera global representada por la ONU en el Bella Center, del ayuntamiento a las puertas de embajadas y corporaciones. Ningún recorrido era neutral. De la ciudad "abierta" y "esperanzada" a otra reformulada en el habla y en el espacio, y que convertía al espacio en un habla social: "Se trata no de hablar en voz alta y a coro por la ciudad, sino a través de ella, como si sus lugares no fueran sólo puntos en un mapa, sino los elementos moleculares de un lenguaje" (Delgado, 2007a, p. 162).

Sila ciudad se resignificaba en las formas del habla y acogía varios nombres en base a experiencias y deseos distintos, también era hablada y reapropiada a través de protestas, marchas y fiestas improvisadas. Por decirlo con Michel de Certeau (1999), se daba una analogía entre las retóricas del habla y las del caminar, siendo análogas estas últimas a las figuras de estilo del lenguaje. Durante el COP15, las caminatas activistas - tanto las rutas pautadas para las manifestaciones como los "atajos" o "frases imprevisibles" tomados para sortear controles policiales, acompañar a las detenidas a prisión o colarse en ruedas de prensa- permitían establecer una relación entre los caminos de la ciudad y los 
de la semántica, pues las vueltas dadas en una hallaban su giro y su plasmación figurada en la otra; es decir, el andar se volvía un espacio de enunciación:

El acto de caminar es al sistema urbano lo que la enunciación (el speech act) es a la lengua o a los enunciados realizados (...) Es un proceso de apropiación del sistema topográfico por parte del peatón, del mismo modo que el locutor se apropia y asume la lengua; es una realización espacial del lugar, del mismo modo que el acto de habla es una realización sonora de la lengua (de Certeau, 1999, p. 110).

De este modo, los juegos del lenguaje establecidos con el espacio urbano y con sus representaciones ponían en entredicho las normas y formas oficiales. Alteraban los usos cotidianos de la ciudad y trastocaban su lectura al emplear un "dialecto geográfico" que desafiaba los requisitos de legibilidad estatal inherentes al planeamiento urbanístico (Scott, 2006). Un ordenamiento de la ciudad que pretende hacerla legible y gobernable, que busca reducir su complejidad por la vía de su homogeneización, y donde se anudan e imbrican cuestiones de poder, saber e identidad (Foucault, 2006; Rabinow, 2003). Así, al proponer una práctica distinta de la urbe, la contracumbre alumbraba una "ciudad metafórica" (DeCerteau, 1999), vivida, narrada y materializada frente al plano y frente al discurso oficial que la ordenaba. Como toda metáfora, esta ciudad se hacía, se rehacía y cobraba sentido en movimiento, capaz - como lo hacen las metáforas- de "re-describir la realidad" (Ricoeur, 1975). Renombrada y reescrita, la ciudad era a un tiempo un espacio textual y un mapa lingüístico, una materialidad que era a la vez semántica.

En este punto, cabe indicar que no existe ciudad que no sea imaginada (Botero, 1997). Al igual que ocurría con la nación europea en su eclosión decimonónica, que se imaginaba como una comunidad política de iguales a través de la lectura de prensa y de novelas - lecturas realizadas desde distintos lugares y por individuos que nunca llegarían a conocerse (Anderson, 1993) —, también la ciudad se imagina mientras se hace y se vive, compuesta de calles tanto como de historias, de plazas tanto como de imaginarios. En el mismo siglo XIX, el París de la revolución forjaba su mito a través de las guías urbanas y las novelas de Émile Zola o Victor Hugo: la revolución se escribía y se inscribía en la ciudad (Ferguson, 1997). Cada mapa un relato, cada nombre en el callejero una historia. El Londres de Charles Dickens o de Arthur Conan Doyle, el viejo Dublín de James Joyce, la Nueva York de Woody Allen o de Federico García Lorca... La ciudad narrada, en novelas o películas, en series de televisión o fotografías, en poemas o carteles de activistas, en las calles o en Internet, es siempre el resultado de una multiplicidad de miradas, lecturas, relatos y subjetividades. Nuestras prácticas en la ciudad inspirarán el lenguaje y el género de nuestras propias narraciones urbanas (Schwarzbürger, 2002). 
Figura 2

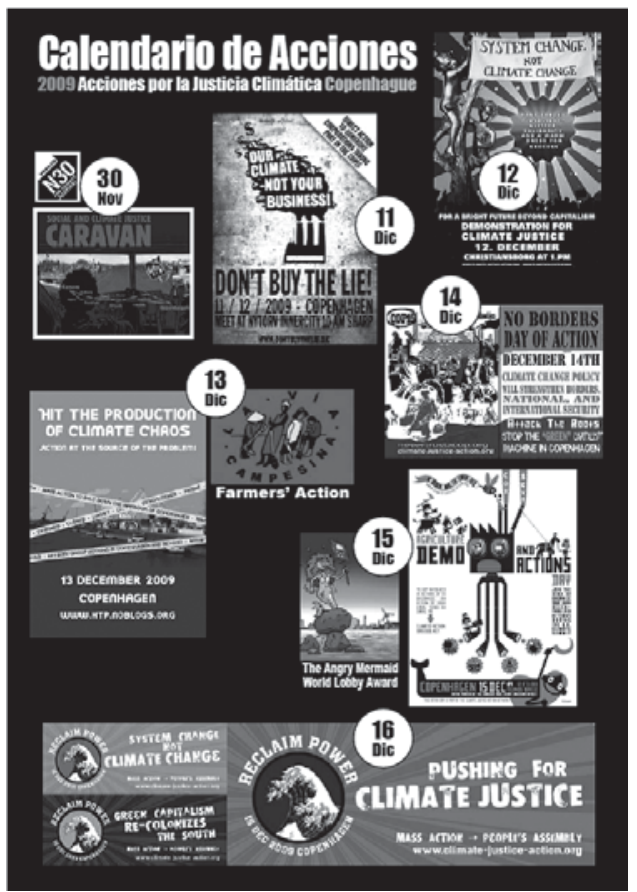

Fuente: La Guía de acciones - climatecollective.org (2009).

\section{FREETOWN CHRISTIANIA: REPENSANDO LA CIUDAD CREATIVA}

Christiania era uno de los sitios operativos de la contracumbre, donde se celebraron asambleas, fiestas y conferencias. Autoproclamado "independiente" en 1971, Freetown Christiania se definía como un "un barrio libre", "un oasis" en el centro de Copenhague. Su población rondaba entonces los 1000 habitantes, que ocupaban 34 hectáreas de lo que en su día fue una instalación militar, abandonada por el ejército danés a finales de los sesenta (Moeller, 2009). Los viejos barracones, reconvertidos en viviendas colectivas, se juntaban con casas autoconstruidas con materiales reciclados; espacios comunes como cines, teatros y salas de conciertos se rodeaban de las últimas murallas del siglo XVII que seguían en pie. Desde su okupación por un grupo de hippies a inicios de los años setenta, este lugar ha funcionado como un espacio de crítica cultural, un nodo en la geografía internacional del activismo (Amouroux, 2009; Vanolo, 2012).

Christiania es una isla, topografía de grandes connotaciones para la literatura utopista. Buena parte de las "ciudades ideales" han sido narradas como 
ínsulas, entre ellas la Utopía de Tomás Moro, en 1516. En este caso, el lugar nació como una comuna, que proponía otra práctica espacio-temporal y sabía que "reencantar el mundo es remoralizarlo" (Gómez-Ullate, 2009, p. 192). Sin embargo, un fallo del Tribunal Supremo en 1976 ordenó el desalojo de estos okupas de la isla, aunque nunca tuvo lugar. En cambio, fue aprobada una ley por la que los socialdemócratas otorgaban al área el reconocimiento de "experimento social", sostenido desde entonces gracias al turismo y a la venta de drogas blandas en su calle principal, Pusher Street (Amouroux, 2009). Contando con servicios propios como guarderías y correo postal, disponiendo de su himno y bandera, durante el COP15 abundaban los negocios dedicados al merchandising. Pese a la polémica que rodea al lugar, Christiania sigue celebrándose como enclave creativo, artístico y alternativo, ideal para que los vecinos paseen junto al lago los fines de semana, aprovechando sus zonas verdes y la ausencia de coches. Todo ello le ha brindado un hueco en las guías de turismo, siendo la segunda "atracción" más visitada en la capital (Vanolo, 2012). Una "ciudad libre y llena de color" cuya visita se vuelve una "verdadera experiencia", donde puedes ver "algo diferente", o eso anuncian las guías consultadas ${ }^{5}$.

Desde su inicio, su estructura interna se inspiró en la "autogestión" y la "democracia directa", tomando decisiones por consenso asambleario. Junto a la producción de bicicletas - la Christiania Bike es una bici de carga comercializada desde los ochenta y muy famosa en Europa-, siempre ha sido la venta de cannabis la actividad económica principal, tolerada por las autoridades hasta hace una década. Hasta entonces, sus residentes podían vender plácidamente en Pusher Street, calle que junto al resto del terreno es propiedad del Ministerio de Defensa. Sin embargo, los acuerdos de 1972 que reconocían el derecho a usar elárea se rompieron en 2004, cuando el liberal Anders Rasmussen - secretario general de la OTAN de 2009 a 2014- manifestó su interés en "regular", "limpiar" y "normalizar" Christiania (Vanolo, 2012).

A partir de ahí se inició el "Plan de Normalización”, estrategia enfocada a privatizar ellugar (Amouroux, 2009). Junto a este, el Project Clean Sweep-proyecto policial de "limpieza a fondo" - articuló prácticas coercitivas (arrestos y redadas), retóricas (criminalizando a los vecinos y tachando a Christiania de "experimento fallido") y de reordenamiento espacial (con demoliciones y expulsiones de población). Aunque el proyecto no obtuvo los resultados esperados, el intento de normalizar Christiania y convertirla en una "zona de tolerancia cero" (Moeller, 2009) ha de contextualizarse en un momento de auge del discurso neoliberal. Un contexto, además, en quela comunidad deviene una nueva espacialización del gobierno, de modo que no sólo emergen más comunidades de resistencia, sino que también tiene lugar una captura gubernamental de lo comunitario (Rose, 2007). Junto a esta captura, el disciplinamiento dela

5 Para másinformación, en línea:http://www.visitdenmark.es/es/copenhague/atracciones/christianiahttp://www. visitcopenhagen.com/copenhagen/sightseeing/alternative-christiania 
isla y la tentativa de transformarla en una "espacialidad neoliberal" — pensada para el mercado - tenía mucho que ver con la introducción del plan Creative Copenhagen, "estrategia que intenta asegurar la posición de Copenhague entre las ciudades europeas, vendiendo una imagen de creatividad empresarial en el Norte" (Amouroux, 2009, p. 119). Sin duda, la privatización resultaba fundamental para atraer inversores al centro urbano, y se ligaba al diseño de una "ciudad creativa". Si bien hasta aquí, en los giros lingüísticos contemplados -el lema turístico de cOPENhagen, la campaña corporativa de Hopenhagen y el grito activista de COPenhagen - la creatividad hacía mella al jugar con palabras y significados, ahora se presentaba como una pauta para el diseño, organización y gobierno de la ciudad.

Desde los noventa, la "creatividad" se ha vuelto una de las keywords en materia de planificación urbana, para algunos el recurso más valioso, como lo fueron el carbón o el acero en la era industrial (Landry, 2012). Conceptos como "ciudad creativa" o "clase creativa", popularizados por Richard Florida $(2009,2010)$, han devenido centrales en los estudios urbanos. Empero, cabe decir que su noción de "clase creativa" se restringe al mundo semi-bohemio de diseñadores y publicistas, informáticos e investigadores, artistas y gentes del espectáculo, arquitectas e ingenieros de software; "trabajadores del conocimiento" de clase media integrados en el llamado capitalismo cognitivo (Fumagalli, 2010), aquel que se caracteriza ya no por la producción de mercancías sino de ideas, saberes y tecnologías. En este contexto se redefinen hoy las nuevas geografías de la centralidad, allá donde las ciudades globales enfrentan una guerra de lugares, compitiendo unas con otras por atraer a este tipo de población (Sassen, 2003).

Una concepción que entiende la innovación, la creatividad y el conocimiento como un conjunto adquirible sólo en base a las nuevas tecnologías de la información, en una visión despolitizada que niega la idea de conflicto social (Alonso \& Fernández, 2013). En este sentido, el nuevo pensamiento urbano ha omitido el carácter anónimo y cotidiano de la creatividad, pensándola monológica y no dialógicamente, y obviando la dimensión múltiple del concepto y sus diferencias entre actores. Por ello, para algunos autores esta concepción de la clase creativa rezuma cierto "elitismo cosmopolita" (Peck, 2005), concepto mistificado que olvida que en tantas ciudades la creatividad se intensifica precisamente entre los más pobres, obligados a ingeniar un sinfín de maneras de salir adelante, siendo además la mano de obra barata que hace posible el trabajo de los creativos (Wilson \& Keil, 2008). Un trabajo que encierra ciertos privilegios y que, podríamos decir, actualiza las nociones de Pierre Bourdieu (1998) sobre el capital social, cultural y simbólico, produciendo y acumulando una suerte de "capital creativo".

En definitiva, cOPENhagen y Creative Copenhagen anhelaban generar una "ciudad marca", promocionada en el mercado global a través del branding urbano. 
Una ciudad con sus fábricas deslocalizadas, ocupando su lugar multinacionales de las telecomunicaciones que sometían a la urbe postindustrial al marketing correspondiente. Un curso de acción que suele ir de la mano de procesos de regeneración urbana, amparados a menudo en el discurso de la cultura y la creatividad. Lo mismo ocurrió en Londres con la Tate Modern, o véase el plan de revitalización que remodeló Bilbao con el museo Guggenheim como eje articulador, o el "modelo Barcelona" iniciado con la villa olímpica (Delgado, 2007b). Un modelo de ciudad "creativa", "moderna" y "cosmopolita" que, en cierto modo, representa la antítesis de la vida urbana, pues se imagina sin contradicciones ni conflictos, aunque genere muy a menudo procesos de gentrificación, recalificaciones del suelo y desplazamientos de población. Todo este giro creativo reconfigura el espacio también sensorialmente, delimitando quién puede estar en él y qué puede hacer allí (Sánchez Fuarros, 2015). Pero además, "promover la ciudad creativa ha implicado el trabajo de producción de su anatomía, de creación de interioridades y recorridos, de fachadas, imágenes y objetos" (Cassián Yde, 2012, p. 182). Esta tendencia produce nuevos imaginarios y subjetividades ("ser creativo", por ejemplo), pero también nuevas materializaciones: "esta producción inmaterial de hecho emerge en condiciones materiales sumamente específicas, de cuerpos, relaciones, accesos a recursos, afectos, prácticas cotidianas, arreglos espaciales y organizaciones específicas del tiempo" (ibíd., p. 185).

En Copenhague, Christiania se erige como comunidad "a la contra" en el muy cotizado centro urbano, y he ahí los repetidos intentos que en la última década buscaron cerrar o "remodelar" el lugar. Habiendo llegado provisionalmente a un acuerdo, Freetown Christiania podría permanecer donde está si logra comprar el terreno antes de 2018. Con todo, llama la atención su caso porque la creatividad se palpa en el ambiente, en las originales esculturas al aire libre, en los coloridos murales, en las soluciones arquitectónicas plasmadas con materiales reciclados y sostenibles, en las casas levantadas por el vecindario, en el diseño de las bicis, en los locales de jazz o en las muestras de arte. El espíritu innovador reclamado por Florida lleva décadas en la isla, visible a través de la economía informal, el trabajo comunitario o la experimentación sociopolítica. Sin embargo, dudo que estos hippies, okupas y activistas - con sus múltiples y sonoras contradicciones - encuentren su sitio en los moldes de la "clase creativa". Christiania ha sido siempre y todavía es una ciudad creativa, salvo que su modelo de creatividad se distancia del que se ha venido impulsando por gobernantes y planificadores urbanos. Un modelo que entiende el espacio como un "contenedor pasivo de externalidades económicas" (Vanolo, 2012,p.3), un terreno vacío a rellenar, ajeno a las prácticas y a los discursos locales. Pero la creatividad no es algo que llegue por encargo ni por efecto de "marca", sino que es a la vez un concepto fluido y situado, flexible y cambiante; no una posesión exclusiva de una clase particular, sino algo consustancial al ser humano. 


\section{CONCLUSIONES}

Después de una semana de manifestaciones y protestas, cansadas y cansados de las detenciones masivas y los combates con la policía, los activistas distribuían carteles que eran pegados en numerosos puntos de la ciudad. En ellos leías: Jokenhagen. Where your voice is under preventive arrest. Hacia el final del COP15, cuando las negociaciones se rompían en el Bella Center y las reticencias de países como China o EE.UU. a reducir las emisiones de gases de efecto invernadero no llevarían más que a la firma in extremis de un pírrico acuerdo sobre el clima, otra vuelta de tuerca se operaba. La "apertura" (cOPENhagen) y la "esperanza" (Hopenhagen) de los lemas oficialistas se tomaban ahora a cachondeo, y Copenhague se convertía de pronto en Jokenhagen, una "ciudad risible", "en broma" o "de chiste", formada a partir de la voz inglesa joke.

Jokenhagen entretejía de nuevo el lenguaje y la ciudad vivida, la semántica y la ciudad practicada, subrayando una capacidad figurativa que movía significantes, desplazaba significados y jugaba con las palabras a partir de las vivencias de aquellos días. He ahí, tan oportuna, la imagen de Ludwig Wittgenstein (1999, p. 13) para describir el lenguaje: "una vieja ciudad: un laberinto de pequeñas calles y plazas". Un lenguaje que - al igual que el espacio urbano- no se habla ni nos hace hablar en el vacío, sino que se incorpora subjetivamente y se carga de moral, acento, intención e ideología. Por ello, para comprender la ciudad narrada resulta útil la noción de heteroglosia (Bajtín, 2004), no sólo para reivindicar la creatividad y versatilidad del hablar cotidiano y su capacidad para renegociar las reglas del habla, sino también para entender el carácter intersubjetivo de la lengua, su construcción coral y diseminada en torno a jergas, grupos, lugares, giros y gustos, influida por el contexto comunicativo de cada interacción. Heteroglosia que indica las múltiples variedades dentro de un código lingüístico. Así, si el lenguaje se hace de calles y plazas, también la ciudad se hace de historias y palabras, de múltiples narraciones. En este sentido, aunque la construcción de la lengua oficial esté vinculada al Estado, ejemplos comolos aquí expuestos subvierten o redireccionan el discurso, maniobrando un détournement dellenguaje (Butler, 2004). Al igual que las calles se convertían en espacios de enunciación, y así como mutaban los nombres y cambiaban los mapas, la práctica activista de la ciudad giraba el lenguaje y giraba, con él, su imaginario urbano.

En definitiva, si “todo relato es un relato de viaje, una práctica del espacio" (De Certeau, 1999, p. 128), narrar la ciudad implica contar sus lugares con una voz hecha praxis; es una forma de producirla e imaginarla, de darle un eco a las prácticas que la recorren, entre la poética y la política de lo vivido. Poco antes de dejar Dinamarca, la seriedad delo que estaba en juegollevaba delabroma(Jokenhagen) a la negación: Nopenhagen. Decir "no" a la cumbre y decir "no" a un modelo de ciudad que se venía fraguando desde hacía tiempo, y que tomó durante el COP15 una forma salvaje. Decir "no" a una ciudad "donde tu voz está en detención preventiva", que ni te interpela ni te deja hablar. No a las medidas de excepción, a las 
detenciones infundadas, al desmesurado control policial, a la privatización, a la exclusión, ala segregaciónyala imparable securitización del medio urbano. Decir no a una ciudad convertida en marca, pensada para el mercado y no para la gente, una ciudad ciega ante el poder dialógico de los múltiples ojos que la leen, y sorda ante el rumor incesante de las múltiples voces que la cuentan.

Los recientes movimientos urbanos, como decíamos al comienzo, se han levantado en los últimos años reclamando otro tipo de gobernanza urbana y proponiendo otras prácticas y otras narraciones de la ciudad. Han visto y han experimentado cómo lo excepcional devenía cotidiano. Han entendido que la ciudad, su lugar de vida, es un objeto político y para la política, un amasijo de relatos y relaciones de poder; no sólo el escenario de la acción sino aquello que está en juego, que se performa a diario entre sitios, cuerpos y palabras.

En una época en que los Estados se distancian de sus poblaciones y pierden legitimidad, las revueltas de la segunda década del siglo XXI — con su intervención material y simbólica en el espacio urbano, repolitizándolo y reimaginándolo - ponen de manifiesto el papel clave que tiene la ciudad a la hora de repensar el papel contemporáneo de la ciudadanía y el valor actual de la democracia. Actúan sobre la ciudad para reescribir su guion urbano, para repensar la trama común que nos atraviesa. La caminan al tiempo que le dan voz. La cuentan y son contados por ella. A través de las plazas, a través de las calles, la ciudad narrada nos invita a tomar el relevo de su crónica, a reescribirla y a contarla de otro modo, con otras voces, con otras palabras. Estamos hechos de historias tanto como de piel y huesos.

\section{REFERENCIAS}

Alonso, L. E. \& Fernández, C. J. (2013). Los discursos del presente. Un análisis de los imaginarios sociales contemporáneos. Madrid: Siglo XXI.

Amouroux, C. (2009). Normalizing Christiania: Project Clean Sweep and the Normalization Plan in Copenhagen. City \& Society, 21(1), pp. 108-132.

Anderson, B. (1993). Comunidades imaginadas. México: Fondo de Cultura Económica.

Baggiolini, L. \& Castro Rojas, S. (2016). Las redes de la política: Universo narrativo, campañas y microrrelato en twitter". InMediaciones de la Comunicación, (11), pp. 159-180. Doi: https://doi.org/10.18861/ic.2016.11.

Bajtín, M. (2004). The Dialogic Imagination. Austin: University of Texas Press.

Balibar, É. (2005). Violencias, identidades y civilidad. Barcelona: Gedisa.

Barthes, R. (2009). Mitologías. Madrid: Siglo XXI.

Beck, U. (2006). La sociedad del riesgo global. Madrid: Siglo XXI. 
Boehnert, J. (4 de septiembre de 2011). Hopenhagen: Design Activism as an Oxymoron. EcoLabs. Design, Ecology, Politics. Recuperado de: http://ecolabsblog.wordpress. com/2011/09/04/hopenhagen-design-activism-as-an-oxymoron/

Botero, L. (1997). Ciudades imaginadas, identidad y poder. Espiral: Estudiossobre Estado y Sociedad, 3, (8), pp. 113-145.

Bourdieu, P. (1998). La distinción. Madrid: Taurus.

Butler,J.(2004).Lepouvoirdesmots. Politique duperformatif. Paris:Éditions Amsterdam.

Caldeira, T. \& Holston, J. (2005). State and Urban Space in Brazil: From Modernist Planning to Democratic Intervention. En A. Ong, \& S. Collier, (Eds.) Global Assemblages (pp. 393-416). Oxford: Blackwell.

Calvino, I. (2013). Las ciudades invisibles. Madrid: Siruela.

Capdepón, F. P. (2015). La evolución de la imagen literaria del paisaje urbano: de la ciudad moderna a la ciudad actual. Estudios Geográficos, 76, (278), pp. 285-307.

Cassián Yde, N. (2012). De qué está hecha una ciudad creativa. Una propuesta para abordar la cultura, el ocio y la creatividad en la urbe contemporánea. Athenea Digital, 12, (1), pp. 169-190.

Castells, M. (1986). La ciudad y las masas. Madrid: Alianza.

Castells, M. (2004). La cuestión urbana. México: Siglo XXI.

Castoriadis, C. (1989). La institución imaginaria de la sociedad. Barcelona: Tusquets.

Cucó, J. (2004). Antropología urbana. Barcelona: Ariel.

Chatterton, P., Featherstone, D. \& Routledge, P. (2012). Articulating Climate Justice in Copenhagen: Antagonism, the Commons, and Solidarity. Antipode, 45, (3), pp. 602-620.

Davis, M. (2001). Control urbano: la ecología del miedo. Barcelona: Virus.

De Certeau, M. (1999). La invención de lo cotidiano. Vol I. México D.F.: Universidad Iberoamericana.

Delgado, M. (2007a). Sociedades movedizas. Barcelona: Anagrama.

Delgado, M. (2007b). La ciudad mentirosa. Madrid: Catarata.

Diz, C. (2016a). Políticasy tácticas del cuerpo: retablos de la ciudad activista. (Tesis inédita de doctorado). Universidade da Coruña, A Coruña.

Diz, C. (2016b). Escuelas de democracia y 15M: participación, redes, ensayos. Revista Educação em Perspectiva, 7, (2), pp. 367-390.

Diz, C. (2017). Los otros lugares de la política: activismo, centros sociales y democracia. En R. Cuenca; W. Gadea; D. Allen-Perkins(Eds.), Haciauna(re)conceptualización de la democracia contemporánea (pp. 143-159). Sevilla: Fénix Editora. 
Douglas, M. (2007). Pureza y peligro. Buenos Aires: Nueva Visión.

Escobar, A. (2000). El lugar de la naturaleza y la naturaleza del lugar: ¿globalización o postdesarrollo? En A. Viola (comp.), Antropología del desarrollo (pp. 169-216). Barcelona: Paidós.

Estalella, A.(17 de marzo de 2016). Auto-instrucción: ciudad, documentación y archivo. (Ponencia en el Festival de Arquitectura FETSAC). Universidade da Coruña, A Coruña.

Farías, I. (2011). Ensamblajes urbanos: la TAR y el examen de la ciudad. Athenea Digital, $11,(1)$, pp. $15-40$.

Ferguson, P. (1997). Paris as revolution: Writing the nineteenth-century city. Berkeley: University of California Press.

Florida, R. (2009). Las ciudades creativas. Barcelona: Paidós.

Florida, R. (2010). La clase creativa. Barcelona: Paidós.

Foucault, M. (2006). Seguridad, territorio, población. México: Fondo de Cultura Económica.

Fukuyama, F. (1992). El fin de la historia y el último hombre. Barcelona: Planeta.

Fumagalli, A. (2010). Bioeconomía y capitalismo cognitivo. Madrid: Traficantes de Sueños.

García Canclini, N. (18 de mayo de 1997). Ciudad invisible, ciudad vigilada. La Jornada Semanal. Recuperado de http://www.jornada.unam.mx/1997/05/18/ sem-nestor.html

García Canclini, N. (2000). La globalización imaginada. Buenos Aires: Paidós.

García Canclini, N. (2007). ¿Qué son los imaginarios y cómo actúan en la ciudad? Eure, 33, pp. 89-99.

Gómez-Ullate, M. (2009). La comunidad soñada. Madrid: Plaza y Valdés.

Hannerz, U. (1998). Conexiones transnacionales. Madrid: Cátedra.

Harvey, D. (1979). Urbanismo y desigualdad social. Madrid: Siglo XXI.

Harvey, D. (2007). Espacios del capital. Madrid: Akal.

Harvey, D. (2013). Ciudades rebeldes. Madrid: Akal.

Holston, J. (Ed.). (1999). Cities and Citizenship. Durham: Duke University Press.

Jackson, M. (2002). Thepolitics of storytelling. Copenhagen: Museum Tusculanun Press.

Juris, J. (2008). Networking futures. Durham: Duke University Press.

Juris, J. (2012). Reflections on \#Occupy Everywhere. Social media, public space, and emerging logics of aggregation. American Ethnologist, 39, (2), pp. 259-279. 
Klein, N. (2001). NO LOGO. Barcelona: Paidós.

Klein, N. (2007). La doctrina del shock. Barcelona: Paidós.

Kuper,H. (2003). The Language of Sites in the Politics of Space. En S.Low, \&D. LawrenceZúñiga (Eds.), The Anthropology of Space and Place (pp. 247-263). Oxford: Blackwell.

Landry, Ch. (2012). The Creative City: A Toolkit for Urban Innovators. London: Earthscan.

Lefebvre, H. (2013). La producción del espacio. Madrid: Capitán Swing.

Moeller, K. (2009). Police crackdown on Christiania in Copenhagen. Crime, Law and Social Change, 52(4), pp. 337-345.

Naciones Unidas (2014). La situación demográfica en el mundo. (Informe conciso ST/ ESA/SER.A/354). Nueva York: Departamento de Asuntos Económicosy Sociales. División de Población.

Peck, J. (2005). Struggling with the Creative Class. International Journal of Urban and Regional Research, 29, (4), pp. 740-770.

Peck, J. (2014). Entrepreneurial urbanism: between uncommon sense and dull compulsion. Geografiska Annaler: Series B, Human Geography, 96(4), 396-401.

Rabinow,P.(2003). Ordonnance, Discipline, Regulation: SomeReflections on Urbanism. En S. Low, \& D. Lawrence-Zúñiga (Eds.), The Anthropology of Space and Place (pp. 353-362). Oxford: Blackwell.

Rancière, J. (2010). Momentos políticos. Buenos Aires: Capital Intelectual.

Reguillón, R. (2008). Saber y poder de representación. La(s) disputa(s) por el espacio interpretativo. Comunicación y sociedad, (9), pp. 11-33.

Ricoeur, P. (1975). La métaphore vive. Paris: Éditions du Seuil.

Rivas, P.(2016).(15 de diciembre de2016). El país que tenía demasiada policía. Diagonal. Recuperado de: https://www.diagonalperiodico.net/libertades/32469-paistenia-demasiada-policia.html

Rodman, M. (2003). Empowering Place: Multilocality and Multivocality. En S. Low, \& D. Lawrence-Zúñiga (Eds.), The Anthropology of Space and Place (pp. 204-223). Oxford: Blackwell.

Rose, N. (2007). ¿La muerte de lo social? Re-configuración del territorio de gobierno. Revista Argentina de Sociología, 5, (8), pp. 111-150.

Sánchez Fuarros, Í. (2015). De barrio maldito a destino cool. Música y rehabilitación urbana en un barrio lisboeta. InMediaciones de la Comunicación 10, (10), pp. 2034. Doi: https://doi.org/10.18861/ic.2015.10

Sassen, S. (2003). Contrageografías de la globalización. Madrid: Traficantes de Sueños. 
Schwarzbürger, S. (2002). La ciudad narrada. Barcelona en las novelas urbanas de Eduardo Mendoza. La relación entre texto y ciudad. Revista de Filología Románica, (3), pp. 203-220.

Sennett, R. (1997). Carne y piedra. Madrid: Alianza.

Soja, E. (2008). Postmetrópolis. Madrid: Traficantes de Sueños.

Tascón, M. \& Quintana, Y. (2012). Ciberactivismo. Las nuevas revoluciones de las multitudes conectadas. Madrid: Catarata.

Vanolo, A. (2012). Alternative Capitalism and Creative Economy: the case ofChristiania. International Journal of Urban and Regional Research, 37, (5), pp. 1785-1798.

Vera, P. (2014). Tecnología, cultura y ciudades. Un aporte conceptual desde los imaginarios sociales. Astrolabio, (12), pp. 106-137.

Villoro, J. (2002). El vértigo horizontal: la ciudad de México como texto. Debats, (78), pp. 67-78.

Wacquant, L. (2010). Castigar a los pobres. El gobierno neoliberal de la inseguridad social. Barcelona: Gedisa.

Wilson, D. \& Keil, R. (2008). The real creative class. Social \& Cultural Geography, 9, (8), pp. 841-847.

Wittgenstein, L. (1999). Investigaciones filosóficas. Madrid: Altaya.

\section{IDENTIFICACIÓN DEL AUTOR}

Carlos Diz es Doctor en Antropología Social y Cultural por la Universidade da Coruña (Galicia, España) y licenciado en Sociología por la misma universidad. Especializado en el área de los movimientos sociales, su trabajo de campo etnográfico se ha desarrollado en distintas zonas de la geografía europea y se ha plasmado en su Tesis Doctoral: Políticas y tácticas del cuerpo: retablos de la ciudad activista. Sus líneas de investigación han girado fundamentalmente en torno a la antropología política, la antropología del cuerpo y la antropología urbana, tratando de estudiar el activismo contemporáneo desde el entrecruzamiento y la interconexión de estos tres ejes principales. Ha sido Investigador Visitante en el Département d'Ethnologie et d'Anthropologie Sociale (Université Bordeaux II) y ha combinado las labores de docencia, publicación e investigación científica con tareas de divulgación en prensa y en otros medios.

\section{REGISTRO BIBLIOGRAFICO}

Diz, Carlos (2017). La ciudad narrada: revuelta y semántica del conflicto urbano. InMediaciones de la Comunicación, 12(1), 191-213. 